\title{
Relevansi Teori Hierarki Kebutuhan Abraham Maslow Terhadap Motiavasi Kerja Anggota Organisasi Penyuluhan Agama Islam
}

\author{
Muhammad Ali Bagas ${ }^{1}$ \\ ${ }^{1}$ Bimbingan dan Penyuluhan Islam, UIN Walisongo Semarang \\ ${ }^{1}$ muhammadalibaggaz@gmail.com
}

$\begin{array}{ccc}\text { First received: } & \text { Revised: } & \text { Final Accepted: } \\ 15 \text { Agustus 2020 } & \text { 02 September 2020 } & \text { 04 November 2020 }\end{array}$

\begin{abstract}
This study aims to describe the relevance of Abraham Maslow's hierarchy of needs theory with the work motivation fellow of Islamic counsell organizations. The research used is; library research that using content analysis as a technique in analyzing related data. The results of this study, namely; Fulfilling the needs of each fellow Islamic counsell organization is one of the causes that can describe the ups and downs of work motivation fellow. The fulfillment needs referred to here, namely; needs formulated by Abraham Maslow, the physiological needs, the safety needs, the belongingness and love needs, the esteem needs, and the need for self-actualization.

Keywords: Work Motivation, Abraham Maslow's Hierarchy Of Needs Theory

Abstrak

Penelitian ini, bertujuan untuk mendeskripsikan relevansi teori hierarki kebutuhan Abraham Maslow dengan motivasi kerja anggota organisasi penyuluhan agama Islam. Penelitian yang digunakan yakni; library Research dengan menggunakan content analysis sebagai tekhnik dalam menganalisis data yang terkait. Hasil dari penelitian ini, yakni; pemenuhan kebutuhan setiap anggota organisasi penyuluhan agama (Islam), menjadi salah satu indikator yang dapat mengebabkan naik dan turunnya motivasi kerja setiap anggota organisasi penyuluhan (Islam). Pemenuhan kebutuhan yang dimaksud disini yakni; kebutuhan yang dirumuskan oleh Abraham Maslow, yang terdiri dari kebutuhan fisiologis (the physiological needs), kebutuhan akan keamanan (the safety needs), kebutuhan dimiliki dan dicintai (the belongingness and love needs), kebutuhan akan penghargaan (the esteem needs), dan kebutuhan untuk mengaktualisasikan diri (the need for self-actualization).

Kata Kunci: Motivasi Kerja, Teori Hierarki Kebutuhan Abraham Maslow
\end{abstract}

\section{PENDAHULUAN}

Sebuah organisasi penyuluhan, tentunya mengharapkan sebuah kinerja yang efektive dari setiap anggotanya. Karna pada dasrnya efektivitas kinerja dari setiap anggota adalah salah satu faktor yang mempengaruhi keberhasilan organisasi dalam mengimplementasikan program yang direncanakan. Efektifitas kinerja anggota itu sendiri, dapat dipengaruhi oleh beberapa aspek. Secara teoritis, terdapat tiga faktor yang dapat mempengaruhinya, yakni; kemampuan dan minat anggota, penerimaan atas tugas yang diberikan, serta peran dan tingkat motivasi kerja dari masing-masing anggota. Sedangkan menurut McClelland dalam Edy Sutrisno mengatakan bahwa, 
harus terdapat dua faktor yang mempengaruhi efektivitas kinerja anggota organisasi, yakni; kemampuan dan motivasi kerja dari setiap anggota yang terkait.

Berdasarkan pada faktor-faktor yang mempengaruhi efektivitas kinerja anggota organisasi, organisasi penyuluhan agama (Islam) memiliki tugas dan tanggungjawab untuk meningkatkan kemampuan, minat, dan motivasi setiap anggotanya, khususnya pada aspek motivasi kerja setiap anggota, karena pada dasarnya motivasi adalah sebuah dorongan dalam diri individu yang dapat menggerakkan seseorang untuk melakukan sesuatu. Menurut Vroom dalam Kreitner \& Kinicki, motivasi dikatakan sebagai suatu hal yang mengarahkan seseorang untuk memutuskan seberapa besar upaya untuk mengerahkan usahanya dalam situasi tertentu.

Sedangkan menurut Hasibuan dalam Fachreza et al, mengatakan bahwa motivasi adalah sebuah pemberian energy penggerak yang melahirkan semangat terhadap individu agar ia mau melakukan sesuatu. Mengacu pada pandangan yang ada, motivasi kerja (work motivation) dapat dimaknai sebagai sebuah dorongan atau energy yang menggerakkan seseorang atau sekelompok orang untuk melakukan dan menyelesaikan pekerjaan. Wekley \& Yunki dalam Kiki Cahaya Setiawan mengatakan, bahwa motivasi kerja (work motivation) adalah "suatu dorongan yang menimbulkan semangat atau dorongan kerja". Sedangkan Terry Mitchell dalam John M. Werner \& Randy L. DeSimone mengatakan bahwa work motivation adalah "the psychological processes that cause the arousal, direction, and persistence of voluntary actions that are goal directed".
Adanya motivasi kerja (work motivation) dalam diri setiap anggota organisasi penyuluhan agama merupakan salah satu aspek penting dari sekian aspek yang lainnya yang harus dikelola, diciptakan, dan dikembangkan kepada setiap anggota dalam organisasi penyuluhan agama. Untuk melihat bagaimana seharusnya motivasi kerja (work motivation) dikelola, diciptakan dan dikembangkan, teori hierarki kebutuhan Abraham Maslow dapat menjadi salah satu sandaran dalam memandang aspek tersebut. Teori Hierarki kebutuhan yang dimaksud, terdiri dari lima bagian, yakni the physiological needs, the safety needs, the belongingness and love needs, the esteem needs, and the need for self-actualization.

Berdasarkan pada uraian yang ada, artikel ini akan menjelaskan mengenai relevansi teori Hierarki kebutuhan Abraham H. Maslow dengan motivasi kerja anggota organisasi penyuluhan agama Islam sebagai suatu gambaran untuk mengelola dan menciptakan serta mengembangkan motivasi kerja kepada para anggota organisasi penyuluhan agama Islam, agar dapat menghasilkan kontribusi positif pada organisasi dan masyarakat sebagaimana tujuan awal dari terbentuknya organisasi penyuluhan agama Islam, yakni; memberikan sebuah pemahaman, arahan dan penerangan, serta pengembangan.

Jenis penelitian yang digunakan dalam mendeskripsikan relevansi teori hierarki Abraham Maslow terhadap motivasi kerja anggota organisasi penyuluhan agama (Islam), yakni; library research. Library research adalah jenis penelitian yang hanya menelusuri bahan-bahan kepustakaan, berupa buku, jurnal, majalah, koran, laporan dan jenis-jenis arsip dokumen lain yang dapat menjadi data dalam penelitian. 
Sedangkan untuk tekhnik yang digunakan dalam menganalisis yakni; content analysis, yang dikatakan sebagai tekhnik analisis dalam penelitian yang memanfaatkan prosedur untuk menarik kesimpulan yang sahih dari sebuah buku atau dokumen yang ada.

\section{HASIL DAN PEMBAHASAN}

\section{Biografi Abraham H. Maslow}

Abraham Harold Maslow (1908-1970 M) Lahir dan besar di Brooklyn, Kota New York, Amerika Serikat pada tanggal 01 April 1908 M. Anak pertama dari tujuh bersaudara, ayahnya bernama Samuel Maslow yang menikah dengan Rose Schilosky. Maslow kecil, adalah sosok seorang anak yang pintar tapi pemalu dan kehidupan masa kecilnya penuh dengan ketidak-bahagiaan. Dari tahun 1934-1935 M, Abraham H. Maslow menerima gelar A.B., M.A. dan Ph.D dari University of Wisconsin serta menjabat sebagai anggota pengajar psikologi. Setelah menjabat di University of Wisconsin, tahun 1935-1937 M, Maslow bergabung dengan fakultas Brooklyn College sebagai pembantu Profesor, dan pada tahun 1951-1961 M, diangkat sebagai ketua Departemen Psikologi di University of Brandeis, kemudian melanjutkan pendidikan sebagai Profesor psikologi.

Tahun 1969 M, Maslow menjadi anggota resident di Yayasan Amal di W. Price Laughlin di Menlo Park, California, dan pernah menjabat sebagai Presiden Asosiasi Psikologi Negara Bagian Massachusetts dan Presiden Asosiasi Psikologi New England, dan pada tahun 1967-1968 M, terpilih sebagai Presiden seluruh Asosiasi ketika menjadi anggota American Psychological Association, sekaligus pernah menjabat sebagai
Presiden Divisi Kepribadian dan Psikologi Sosial, Presiden Divisi Esthetics ketika bergabung sebagai Anggota di American Psychological Association. Berangkat dari banyaknya prestasi, kontribusi, dan pengalamannya, Abraham Maslow dianugrahi gelar kehormatan D. Leg oleh Xavier University pada tahun 1965 M, dan pada tahun 1970 M, Abraham Maslow meninggal dunia karna serangan jantung.

Ketertarikan Abraham Maslow pada bidang psikologi, menjadikan ia sebagai salah satu tokoh psikologi yang ternama. Berangkat dari ketertarikannya tersebut, ia banyak mempelajari teori psikologi (psikoanalisis dan behaviorisme), kemudian mengantarkan ia pada suatu konsep teori psikologi baru (humanistik), yang dikatakan sebagai Mazhab ketiga psikologi. Melalui rumusan mengenai psikologi humanistik, Abraham Maslow berupaya membawa psikologi berfokus pada potensi manusia secara utuh. Ia memiliki pandangan bahwa manusia harus didorong untuk mengaktualisasikan potensinya secara optimal, manusia adalah makhluk yang terintegrasi secara penuh, aspek-aspeknya tidak dapat dipisahkan antara satu dengan yang lainnya, dan dapat mencapai tingkat tertinggi dalam kehidupannya (kemampuan transendensi), manusia mampu berkembang mencari batas kreativitasnya, berkembang menuju pencapaian tertinggi dari kesadaran dan kebijaksanaan.

Sebagai seorang psikolog, Abraham H. Maslow (1908-1970 M) adalah salah satu tokoh aliran psikologi humanistik yang memiliki kepercayaan bahwa setiap manusia memiliki kehendak bebas (free will) untuk menyusun tujuan dan masa depannya. Salah satu teorinya yang terkenal yakni, berhubungan dengan motivasi manusia (teori Hierarki 
kebutuhan). Ia menyusun tori motivasi manusia, yang mana menurutnya, bahwa variasi kebutuhan manusia tersusun dalam bentuk Hierarki atau berjenjang. Setiap jenjang tersebut, akan dapat dipenuhi jika jenjang sebelumnya telah relatif dapat terpuaskan.

\section{Relevansi Motivasi Kerja dengan Teori Hierarki Kebutuhan Abraham Maslow}

Sebuah organisasi penyuluhan agama (Islam), tidak pernah bisa terlepas dari dinamika. Ia bagaikan organisme (living system) yang harus dipertahankan oleh anggota yang ada didalamnya, agar mampu mencapai tujuan yang diharapkan. Anggota adalah roda penggerak sebuah organisasi, yang berperan sebagai orangorang yang menggerakkan organisasi. Oleh karenanya setiap anggota dituntut untuk aktif, kereatif, dan inovatif dalam menjalankan tugas dan tanggungjawab yang telah diberikan. Pada konteks pemenuhan tugas dan tanggungjawab tersebut, motivasi kerja menjadi salah satu aspek penting dalam organisasi yang harus diperhatikan, karna pada dasarnya motivasi kerja berhubungan dengan dorongan pada anggota untuk mencapai tujuan yang telah disepakati bersama.

Sebuah motivasi terlahir akibat adanya kebutuhan, seperti yang dikatakan oleh Abraham Maslow, bahwa motivasi adalah sebuah dorongan yang terlahir dari dalam diri seseorang sebagai suatu kesatuan yang terpadu dan memiliki tujuan atau keinginan tertentu, yakni mewujudkan kebutuhan manusiawi sehingga tidak dapat dilepaskan dari kehidupan tidak sadar. Pada konteks motivasi kerja anggota organisasi penyuluhan agama (Islam), implikasi positif dari teori Hierarki kebutuhan Abraham Maslow, sebagai berikut;

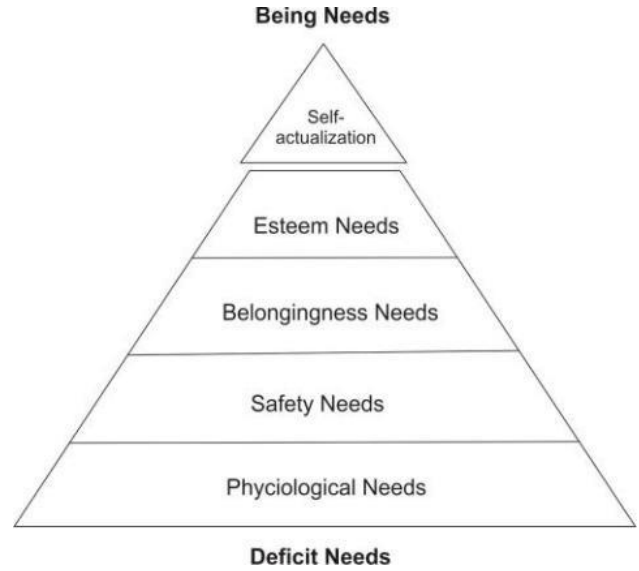

Kebutuhan pertama, dikatakan sebagai kebutuhan fisiologis (physiological needs), yakni; kebutuhan paling dasar dari manusia yang mencakup kebutuhan air dan makanan, oksigen, seks, dan semua elemen-elemen fisik yang mendukung kehidupan manusia. Abraham Maslow memandang kebutuhan fisiologis ini, sebagai kebutuhan yang paling dasar dan mondominasi manusia untuk melakukan suatu tindakan tertentu dan bersifat homeostatik, yakni suatu usaha untuk menjaga keseimbangan unsur-unsur fisik manusia. Misalnya, seorang yang sangat lapar dan haus, tidak akan ada kepentingan lain selain memenuhi rasa lapar dan hausnya, baik itu bahwa rasa lapar dan hausnya dalam kebiasaanya ia penuhi dengan makanan dan minuman ataupun yang lainnya, seperti seseorang yang merasa kenyang hanya dengan membuat puisi, cerita atau dengan meminum kopi dan merokok saja.

Pada sisi yang lain physiological needs dikatakan juga sebagai kebutuhan yang dapat dipakai untuk memuaskan kebutuhan jenjang yang lebih tinggi, misalnya seperti seseorang yang stres karna cintanya tidak terpuaskan, sehingga ia memilih untuk makan, minum ataupun merokok terus-menerus untuk memuaskannya. Karna pada dasarnya physiological needs adalah satu-satunya kebutuhan yang bisa dipenuhi secara 
berlebihan dan kebutuhan ini bersifat recurring atau berpola terus-menerus (setelah seseorang makan, ia dapat merasakan lapar lagi).

Berdasarkan pada uraian tersebut, dalam organisasi penyuluhan agama (Islam), kebutuhan ini, berhubungan dengan kesejahteraan anggota-anggota organisasi yang harus menjadi prioritas utama. Misalnya, gaji bulanan, kenyamanan ruangan atau tempat kerja, serta hal-hal yang berhubungan dengan kebutuhan fisiologis anggota organiasi. Pemenuhan kebutuhan fisiologis kepada anggota organisasi menjadi point utama yang harus dapat terpenuhi dengan maksimal untuk meningkatkan motivasi kerja para anggota organisasi. Apabila kebutuhan fisiologis relative tidak terpenuhi pada anggota organisasi, akan dapat terjadi kekosongan motivasi kerja dari para anggota yang dapat menimbulkan hambatan pola kerja di dalam organisasi.

Setelah pemenuhan kebutuhan fisiologis relative dapat terpenuhi. Motivasi kerja akan dapat lebih efektif jika kebutuhan yang kedua, yakni kebutuhan akan keamanan (sefety needs) relative dapat terpenuhi pada anggota organisasi. Kebutuhan keamanan (safety needs), berhubungan dengan keamanan (fisik dan psikologis). Keamanan yang berhubungan dengan aspek fisik mencakup keamanan ditempat anggota organiasi berkerja, dan keamanan dari dan ke tempat anggota organisasi akan bekerja. Sedangkan, keamanan dari aspek psikologis dapat digambarkan seperti perlakuan yang adil terhadap anggota organisasi, sikap dan perlakuan yang manusiawi, jaminan akan kelangsungan pekerjaan, hari tua, dan aspek-aspek lain yang berhubungan dengan aspek psikologis para anggota organisasi. Kebutuhan ini pada dasarnya merupakan kebutuhan yang sama dengan kebutuhan fisiologis (physiological needs), yakni; sama-sama bertujuan untuk mempertahankan hidup, namun berbeda pada aspek tujuannya. Kebutuhan akan rasa aman (safety needs), bertujuan sebagai pertahanan hidup jangka panjang, sedangkan kebutuhan fisiologis (physiological needs), bertujuan sebagai pertahanan hidup jangka pendek. Kebutuhan keamanan, terdiri dari kebutuhan akan keselamatan, stabilitas, ketergantungan, perlindungan, kebebasan dari rasa takut dan kekacauan, kebutuhan akan struktur, keteraturan, hukum, batasan, kuat dalam perlindungan dan seterusnya.

Kebutuhan akan keamanan ini, sudah muncul semenjak manusia itu dilahirkan ke dunia. Abraham Maslow mengatakan dalam bukunya Motivation and Personality, seorang bayi akan bereaksi secara total dan seolah-olah mereka terancam punah (menangis dan berteriak) ketika diperlakukan kasar atau karna didasari oleh perlakukan yang dirasakan sebagai sumber bahaya, misalnya merasa terganggun atau dijatuhkan tiba-tiba, terkejut oleh bunyi suara yang keras, cahaya berkedip, hilangnya dukungan ibu, atau adanya dukungan yang tidak memadai. Gambaran tersebut, adalah suatu representasi yang menunjukkan bahwa setiap manusia dalam menjalankan kehidupannya tidak hanya membutuhkan physiological needs, melainkan manusia juga membutuhkan safety needs seperti yang digambarkan oleh Abraham Maslow.

Oleh karenanya, sebuah organisasi penyuluhan agama (Islam) harus memiliki kerangka penjamin keselamatan yang nantinya dapat berimplikasi pada keselamatan setiap anggotanya dalam mengerjakan tugas dan tanggungjawab 
yang telah diberikan. Misalnya adanya aturan-aturan atau budaya-budaya tertentu yang diterapkan dalam organisasi, seperti dilarang mencuri, harus berpakaian rapi ketika melaksanakan tugas atau tanggungjawabnya, dilarang membawa senjata tajam, obat-obat terlarang, dan lainlain yang berhubungan dengan rasa keamanan dan kenyamanan anggota organisasi penyuluhan agama (Islam).

Organisasi sebagai sebuah wadah yang dibuat secara sengaja, tersistem, terorganisir, dan terstruktur dengan tujuan tertentu, perlu juga memperhatikan kebutuhan ketiga, yang dinamakan oleh Abraham Maslow sebagai belongingness and love needs, setelah terpenuhinya safety needs dan physiological needs, relative terpuaskan. Karna pada dasarnya, manusia (anggota organisasi) adalah makhluk sosial dan makhluk yang sangat peka dengan kesendirian, pengasingan, penolakan lingkungan, serta kehilangan sahabat atau kehilangan cinta. Pada kebutuhan ketiga ini, cinta dibagi menjadi dua bagian, yakni; deficiency love dan being love. Deficiency love adalah cinta yang hanya mementingkan dirinya sendiri, lebih memperoleh daripada memberi. Contohnya, seseorang yang mencintai sesuatu yang tidak dimilikinya, seperti harga diri, seks, atau suatu hal yang membuat dirinya menjadi tidak sendirian. Sedangkan being love adalah cinta yang tidak berniat memiliki, tidak mempengaruhi dan bertujuan memberikan orang lain gambaran positif, penerimaan diri, dan perasaan dicintai, yang membuka perasaan seseorang untuk berkembang.

Mendapatkan suatu penghargaan ataupun cinta dari seseorang atau banyak orang adalah suatu kebanggaan tersendiri yang dapat memotivasi manusia lebih produktif lagi dalam melakukan sesuatu. Hal ini, berlaku juga bagi para anggota organisasi, dengan adanya pemberian penghargaan ataupun cinta kepada anggota organisasi akan dapat membuat mereka lebih produktif dalam mengerjakan tugas dan tanggungjawab yang ada. Pemberian penghargaan ataupun cinta kepada para anggota organisasi dapat dilakukan dengan beberapa hal, diantaranya; pemberian intensif khusus kepada anggota, tunjangan jabatan fungsional yang memadai, menjenguknya ketika sakit, dan memberikan dukungan ketika memiliki suatu permasalahan, serta bisa juga berupa pemberian beasiswa untuk meningkatkan sumber daya manusianya.

Kebutuhan keempat, diistilahkan sebagai esteem needs, yakni; kebutuahn yang tidak kalah pentingnya bagi organisasi dalam meningkatkan, mengelola, dan mengembangkan motivasi kerja pada setiap anggotanya. Kebutuhan ini mencakup harga diri, kepercayaan diri, kompetensi diri, dan rasa dihargai oleh orang lain. Abraham Maslow mengatakan, esteem needs, terbagi menjadi dua bagian, yakni; self respect dan respect from others. self-respect didefiniskan sebagai suatu keinginan untuk mencapai kekuatan, prestasi, keberhasilan, kesuksesan, kecukupan, kepercayaan diri dalam menghadapi dunia, dan untuk kebebasan dan kemerdekaan. Sedangkan respect from others didefinisikan sebagai suatu keinginan untuk mendapatkan reputasi atau prestise (sebagai rasa hormat atau penghargaan dari orang lain), pengakuan, perhatian, penting atau apresiasi.

Penerapan kebutuhan yang ke-empat (esteem needs), pada anggota-anggota organisasi untuk meningkatkan motivasi kerja, salah satunya dapat dilakukan 
dengan memberikan ruang kebebasan kepada para anggota untuk mengexsplorasi potensi yang dimilikinya, diberikan kebebasan dalam menyampaikan pendapat, sehingga para anggota organisasi dapat memudahkan dirinya untuk mencapai kebutuhan kelima, yakni aktualisasi diri (selfactualization) yakni kebutuhan yang dikatakan sebagai kebutuhan-kebutuhan puncak. Self-actualization, seperti yang dikatakan oleh Abraham Maslow, mengarah pada hal-hal yang dikatakan sebagai motivasi-motivasi paling tertinggikreativitas, kepedulian, apresiasi atas keindahan, kebenaran, keadilan, dan seterusnya.

Mengenai self-actualization, Abraham Maslow juga mengatakan dalam Hendro Setiawan, "seorang pemusik harus menciptakan music, seorang pelukis harus melukis, seorang penyair harus bersyair, jika mereka mau berdamai dengan dirinya sendiri". Ungkapan ini, mengarah pada pemahaman bahwa self-actualization adalah kebutuhan setiap anggota organisasi untuk melakukan apa yang menjadi tujuan awal mereka masuk dan bergabung dalam sebuah organisasi. Melalui uraian yang ada, motivasi kerja (work motivation) dengan teori hierarki kebutuhan yang dirumuskan oleh Abraham Maslow dan kawan-kawan memiliki relevansi dalam menyusun, merumuskan, mengembangkan, dan meningkatkan motivasi kerja kepada anggota organisasi penyuluhan agama (Islam).

\section{KESIMPULAN}

Organisasi penyuluhan agama (Islam), adalah organisasi yang dibuat secara sengaja, terstruktur, tersistematis, dan terorganisir. Terbentuknya organisasi ini, bertujuan untuk memberikan suatu pencerahan, pemahaman dan pengetahuan, serta sebagai wadah yang berperan untuk membantu masyarakat dalam menyelesaikan persoalan yang dihadapi, khususnya yang berhubungan dengan aspek keagamaan. Untuk mencapai tujuan tersebut, sebuah organisasi penyuluhan tentunya harus dapat mengelola, mengembangkan, anggotaanggotanya yang menjadi penggerak organisasi itu sendiri. Karena, pada dasarnya hal ini menjadi salah satu jalan untuk mencapai tujuan yang telah disepakati bersama dalam organisasi. Salah satu cara dalam mewujudkan hal tersebut, yakni dengan cara memenuhi setiap kebutuhan anggota organisasi yang dirumuskan oleh Abraham Maslow sebagai berikut, yakni; the physiological needs, the safety needs, the belongingness and love needs, the esteem needs, and the need for self-actualization.

\section{DAFTAR PUSTAKA}

Arifin, Zainal Isep. Bimbingan Penyuluhan Islam: Pengembangan Dakwah Melalui Psikoterapi Islam. Jakarta: Rajawali Press, 2009.

Alwisol. Psikologi Kepribadian, Edisi Revisi. Malang: UMM Press, 2009.

Ambarwati, Arie. Prilaku Dan Teori Organisasi. Malang: Media Nusa Creative, 2018.

Boeree, George. General Psychology Ke 2. Jogjakarta: Prismasophie, 2017.

Clements, Thomson Carol. "The Right to Be Human: A Biography of Abraham Maslow." Journal of Music Therapy 27, no. 1 (1990).

Corey, Gerald. Teori Dan Praktek Konseling \& Psikoterapi. Bandung: Refika Aditama, 2013. 
Effendhie, Machmoed. Pengantar Organisasi, n.d. Fachreza et al. "Pengaruh Motivasi Kerja, Lingkungan Kerja, Dan Budaya Organisasi Terhadap Kinerja Karyawan Dan Dampaknya Pada Kinerja Bank Aceh Syariah Di Kota Banda Aceh." Jurnal Magister Manajemen Fakultas Ekonomi Dan Bisnis Unsyiah 2, no. 1 (2018).

Freud, Sigmund. The Ego and The Id, Terj.

Nor. Cholish. Yogyakarta: Utama Offset, 2018.

Feist, Jess \& Gregory J. Feist. Teori Kepribadian (Theories of Personality). Jakarta: Salemba Humanika, 2010.

Hasibuan, Malayu S.P. Manajemen Sumber Daya Manusia. Jakarta: Bumi Aksara, 2009.

Irwanto \& Felicia Y Gunawan. Sejarah Psikologi: Perkembangan Perspektif Teoritis. Jakarta: Gama Media Pustaka Utama, 2018.

Iskandar. "Implementasi Teori Hirarki Kebutuhan Abraham Maslow Terhadap Peningkatan Kinerja Pustakawan." Khizanah Al-Hikmah 4, no. 1 (2016).

Kreitner, R. \& A. Kinicki. Organizational Behavior. 7th ed. New York: Mc Graw Hill, 2007.

Moleong, Lexy J. Metode Penelitian Kualitatif. Bandung: PT Remaja Rosda Karya, 2011.

Maslow, Abraham. "A Science Odyssey; People and Discoveries." Www.Pbs.Org, n.d.

- - - "A Theory of Human Motivation." Psychological Review 50, no. 4 (1943). https://doi.org/10.1007/978-3-03036875-3_12.
- - . "Abraham H. Maslow: A Bibiliography." Journal Humanistic Psychology 10, no. 2 (1970).

- - Motivation and Personality. English Ed. Harper \& Row, Inc, 1954.

Noor, Wahyudi Kamal \& U’um Qomariyah. "Hierarki Kebutuhan Sebagai Dasar Refleksi Diri Tokoh Dalam Novel Pesantren Impian." Jurnal Sastra Indonesia 8, no. 2 (2019).

Rakhmat, Jalaluddin. Psikologi Komunikasi. Edisi Revi. Bandung: Simbiosa Rekatama Media, 2018.

Setiawan, Kiki Cahaya. "Pengaruh Motivasi Kerja Terhadap Kinerja Karyawan Level Pelaksana Di Divisi Operasi PT. Pusri Palembang." Jurnal Psikologi Islami 1, no. 2 (2015).

Sintaasih, Wayan Gede Supartha \& Desak Ketut. Pengantar Prilaku Organisasi, Teori, Kasus Dan Aplikasi Penelitian. Denpasar Timur: Setia Bakti, 2017.

Sutrisno, Edy. Manajemen Sumber Daya Manusia. Jakarta: Kencana, 2009.

Sari, Elisa \& Rina Dwiarti. “Pendekatan Hierarki Abraham Maslow Pada Prestasi Kerja Karyawan PT. Madubaru (PG Madukismo) Yogyakarta." Jurnal Prilaku Dan Strategi Bisnis 6, no. 1 (2018).

Setiawan, Hendro. Manusia Utuh Sebuah Kajian Atas Pemikiran Abraham Maslow. Yogyakarta: Kanisius, 2014.

Werner, John M. \& Randy L. DeSimone. Human Resource Development. SouthWestern: Cengage Learning, 2012.

Wardalisa. "Teori Hirarki Kebutuhan Abraham Maslow," 2013. Zed, Mestika. Metode Penelitian 
Relevansi Teori Hierarki... - Muhammad Ali Bagas

Kepustakaan. Jakarta: Yayasan Pustaka Obor Indonesia, 2014.

Sparrow, D.G. (2010). Motivasi Bekerja dan Berkarya. Jakarta: Citra Cemerlang. 